\title{
Diaphragmatic myasthenia in mother and child
}

\author{
Anne K. Mier and C.W.H. Havard \\ The Royal Free Hospital, Pond Street, London NW3 2QG, UK.
}

\begin{abstract}
Summary: A 28 year old patient with ocular myasthenia for 2 y gave birth to a baby with diaphragmatic weakness. Following delivery the mother developed severe weakness of the diaphragm and required assisted ventilation. The baby recovered spontaneously and the mother responded to treatment with plasma exchange and immunosuppression. Neither mother nor baby responded to anticholinergic drugs and in neither serum were acetyl choline receptor antibodies detected.
\end{abstract}

\section{Introduction}

Myasthenia gravis is an auto-immune disease characterized by fatiguable muscle weakness. The number of functioning acetyl choline receptors (AChR) at the neuromuscular junction is reduced because of destruction by IgG auto-antibodies (anti-AChR)(Drachman, 1978). A clinical diagnosis of myasthenia may be confirmed by (1) a positive test performed with edrophonium chloride; (2) the presence of anti-AChR in the patient's serum; and (3) electromyography (EMG) of affected muscle which shows decrementing motor action potentials in response to repetitive nerve stimulation; single fibre electromyography is also useful to show 'jitter' which is a feature of defective neuromuscular transmission.

We describe a patient with myasthenia gravis in whom anti-AChR were not found, and in whom the muscle weakness was atypical in that it was localized to the diaphragm and in that it did not respond to anticholinergic drugs. The problems of establishing a diagnosis were therefore considerable. The patient gave birth to a baby who was affected by transient neonatal myasthenia, in whom the weakness was also confined to the diaphragm and who required assisted ventilation for over 2 weeks.

\section{Case report}

A 28 year old West Indian model was well until July 1980 when she developed transient drooping of the left eyelid and diplopia. A clinical diagnosis of ocular myasthenia gravis was made but there was no response to edrophonium or pyridostigmine and anti-AChR antibodies measured by radio-immunoassay were negative (Lindstrom et al., 1976). Her symptoms were

Correspondence: C.W.H. Havard, D.M., F.R.C.P. Accepted: 17 January 1985 mild and remitted and she did not require any treatment.

In September 1981 she became pregnant and after the 30th week of gestation she began to complain of occasional breathlessness. There was no recurrence of ocular myasthenia. At 37 weeks gestation her vital capacity was 1.2 litres. Labour was induced at 38 weeks and a live baby boy was born by forceps delivery. However, he made no respiratory effort at birth and required intubation and ventilation. Limb power was normal but there was paradoxical movement of the abdomen suggesting diaphragmatic paralysis. Intravenous edrophonium produced no clinical improvement.

Following delivery, the mother became increasingly dyspnoeic especially when lying flat. On day 12 post partum her vital capacity had fallen to $400 \mathrm{ml}$ standing and was unrecordable when supine. Blood gases revealed $\mathrm{pH} 7.25, \mathrm{PO}_{2} 7.8 \mathrm{kPa}(58.5 \mathrm{~mm} \mathrm{Hg})$ and $\mathrm{PCO}_{2} 8.7 \mathrm{kPa}(65.2 \mathrm{~mm} \mathrm{Hg})$. She did not respond to intravenous edrophonium and required intubation and intermittent positive pressure ventilation. Electrophysiological testing with repetitive nerve stimulation of the triceps muscle at a rate of $3 / \mathrm{s}$ showed no fatiguability. The diagnosis of myasthenia gravis was established by demonstrating reduced miniature end plate potentials (MEEP) on intercostal muscle biopsy (MEPP $=0.45 \pm 0.09 \mathrm{mV}$, normal, more than $1 \mathrm{mV}$ ). Diaphragmatic weakness was demonstrated by measuring transdiaphragmatic pressure during a maximal static inspiratory effort with gastric and oesophageal balloon catheters. The maximum pressure change was greatly reduced at $6 \mathrm{~cm} \mathrm{H}_{2} \mathrm{O}$ (normal>. $25 \mathrm{~cm} \mathrm{H}_{2} \mathrm{O}$ ). Despite the absence of demonstruble anti-AChR, plasma exchange was performed and treatment with azathioprine and prednisolone was commenced. Four days after the final plasma exchange she was able to breathe alone during the day 
but continued to require ventilatory support at night until 10 weeks post partum. Prior to discharge there was no demonstrable diaphragmatic weakness, ptosis or diplopia. Her vital capacity was 1.7 litres when supine and blood gases were normal.

Diaphragmatic fatiguability was also demonstrated in the baby who required ventilatory support for $18 \mathrm{~d}$ but then made a spontaneous recovery.

At follow up 15 months later, both the baby and mother were well. The mother had no demonstrable weakness and her only treatment was azathioprine $150 \mathrm{mg}$ o.d. and prednisolone $15 \mathrm{mg}$ o.d. Since she remains asymptomatic consideration of thymectomy has been deferred.

\section{Discussion}

The diaphragm is the principal muscle of respiration being responsible for about $75 \%$ of inspiration during quiet breathing (Loh et al., 1977). Diaphragmatic weakness results in considerable respiratory difficulty which is most marked in the supine position (McCredie et al., 1962). Examination of the patient lying supine reveals paradoxical inward motion of the abdomen during inspiration and the patient's vital capacity, which may initially be low, falls by more than $25 \%$ in the supine position. Diaphragmatic dysfunction in this patient was confirmed by finding diminished pressure changes across the diaphragm during a maximum inspiratory effort (Pdi PI max), pleural and intra-abdominal pressures being measured simultaneously using oesophageal and gastric balloon catheters (Agostini \& Rahn, 1960).

This patient's myasthenia was atypical in that the diaphragm was the only muscle significantly affected. In addition, the edrophonium test was negative and she did not respond to anti-cholinesterase drugs, antiAChR antibodies were not detected in the serum and the electromyogram was normal after repetitive nerve stimulation.

In patients with purely ocular myasthenia failure to respond to anticholinesterase drugs is well recognized but is unusual in a patient with more generalized myasthenia (Perlo et al., 1960).

Since the diaphragm was principally affected in this patient, it is perhaps not surprising that electromyograms performed on unaffected peripheral muscles showed no fatiguability. The diagnosis of myasthenia was confirmed by finding a reduction in the size of miniature-end plate potentials (MEPP) on intercostal muscle biopsy (Lambert et al., 1976). Intercostal muscles are biopsied to provide whole fibres on which the electrophysiology of neurotransmission can be tested. When acetyl choline is released from a nerve ending and crosses the synapse to bind with AChR at the post synaptic membrane MEPP are produced. A normal MEPP is more than $1 \mathrm{mV}$ in size and the finding of a reduction in its size is characteristically found in myasthenia gravis. In addition, cholinesterase staining of the biopsy showed elongation of the post synaptic membrane of the neuromuscular junction, a change also typical of myasthenia gravis (Engle et al., 1976).

Antibodies to AChR are found in $87 \%$ of patients with generalized myasthenia (Lindstrom et al., 1976). Antibody titres in large groups of patients show no correlation with the severity of the disease but patients with purely ocular myasthenia have the lowest titres. However, in an individual patient clinical improvement is associated with a progressive decrease in antibody titre (Newsom-Davis et al., 1978). Readings close to zero are found in normal individuals and in patients with other neurological diseases (Lindstrom et al., 1976).

There are three mechanisms by which anti-AChR antibodies interfere with neuromuscular transmission. Complement mediated lysis of the post synaptic membrane is probably the most important. Secondly an enhanced rate of degradation of AChR does occur as a result of cross-linking by antibody. The average AChR has a life of about $7 \mathrm{~d}$ in a normal individual whilst in a myasthenic patient the life of the receptor is reduced to 1 day. Thirdly, antibodies directed against the acetylcholine binding site may inhibit AChR function. Such antibodies have been demonstrated by the reduction of bungarotoxin binding to human AChR by myasthenic sera (Newsom-Davis et al., 1978). Such antibodies would not be detected by the radioimmunoassay of Lindstrom et al. (1976) as the assay uses as antigen a crude detergent extract of human muscle in which the AChR are labelled with radio-iodinated bungarotoxin.

Although anti-AChR antibodies were not detected in our patient, her response to plasma exchange and the transient signs in the infant supported the fact that a circulating factor was responsible. It would therefore seem probable that this patient had developed antibodies directed against the AChR binding site. Furthermore, the mother's condition deteriorated rapidly after delivery. This is often found in patients with myasthenia gravis and in patients with other diseases characterized by auto-antibodies such as immune thyroid disease (Davies \& Weiss, 1981; Hardisty \& Munro, 1983).

Neonatal myasthenia gravis is a transient form of myasthenia gravis. It appears in about $20 \%$ of babies born to myasthenic mothers and is due to placental transfer of IgG antibodies to AChR from mother to baby (Warren \& Planche, 1979). Receptor antibodies are usually demonstrated in the blood of both mother and baby (Keesey et al., 1977; Donaldson et al., 1981). As the titre falls the baby recovers. Mothers with low titres tend to have unaffected babies (Donaldson et al., 
1981). The onset of weakness usually takes several hours to develop and lasts on average $18 \mathrm{~d}$. In this case, weakness was present at birth. The timing of symptoms possibly relates to maternal medication. The usual delay may be due to anticholinesterase drugs having been given to the mother which cross the placenta and therefore protect the baby for several hours after birth until the level of the drug diminishes. Our patient did not receive anticholinesterase drugs and this may explain why her baby was weak immediately at birth. Other unusual features in this infant were that he had no facial or ocular in-

\section{References}

AGOSTONI, E. \& RAHN, H. (1960). Abdominal and thoracic pressures at different lung volumes. Journal of Applied Physiology. 15, 1087.

DAVIES, T. \& WEISS, I. (1981). Autoimmune thyroid disease and pregnancy. American Journal of Reproductive Immunology, 1, 187.

DONALDSON, J.O., PENN, A.S., LISAK, R.P., ABRAMSKY, O., BRENNER, T. \& SCHOTLAND, D.L. (1981). Anti-acetylcholine receptor antibody in neo-natal myasthenia gravis. American Journal of Diseases of Childhood, 135, 222.

DRACHMAN, D.B. (1978). Myasthenia gravis. New England Journal of Medicine, 298 (3), 136.

ENGEL, A.G., TSUJIHATA, M., LINDSTROM, J.M. \& LENNON, V.A. (1976). The motor-end plate in myasthenia gravis and in experimental autoimmune myasthenia gravis. A quantitative ultrastructural study. Annals of the New York Academy of Science, 274, 60.

FAMBROUGH, D.M., DRACHMAN, D.B. \& SATYMURTI, S. (1973). Neuromuscular junction in myasthenia gravis: decreased acetylcholine receptors. Science, 182, 293.

HARDISTY, C.A. \& MUNRO, D.S. (1983). Serum long-acting thyroid stimulator protector in pregnancy complicated by Graves' disease. British Medical Journal, 286, 934.

KEESEY, J., LINDSTROM, J., COKELY, H. \& HERRMANN, C. (1977). Anti-acetylcholine receptor antibody in neo-natal myasthenia gravis. New England Journal of Medicine, 296, 55. volvement, the weakness being confined to the diaphragm and that he did not respond to anticholinesterase drugs.

\section{Acknowledgements}

We should like to thank Professor J. Newsom-Davis, Dr D. Brown and the staff of I.T.U. at the Royal Free Hospital for their help in the care of this patient, Dr L. Loh, for measuring transdiaphragmatic pressures and Mr Richard Hayward for performing the intercostal muscle biopsy.

LAMBERT, E.H., LINDSTROM, J.M. \& LENNON, V.A. (1976) End-plate potentials in experimental autoimmune myasthenia gravis in rats. Annals of the New York Academy of Science, 274, 300.

LINDSTROM, J.M., SEYBOLD, M.E., LENNON, V.A., WHITTINGHAM, S. \& DUANE D.D. (1976). Antibody to acetylcholine receptor in myasthenia gravis: prevalence, clinical correlates and diagnostic values. Neurology, 26, 1054.

LOH, L., GOLDMAN, M. \& NEWSOM-DAVIS, J. (1977). The assessment of diaphragmatic function. Medicine, 56, 165.

MCCREDIE, M., LOVEJOY, F.W. \& KALTREIDER, N.L. (1962). Pulmonary function in diaphragmatic paralysis. Thorax, 17, 213.

NEWSOM-DAVIS, J., PINCHING, A.J., VINCENT, A. \& WILSON, S.G. (1978). Function of circulating antibody to acetylcholine receptor in myasthenia gravis: investigation by plasma exchange. Neurology, 28 (3), 266.

PERLO, V.P., POSKANZER, D.C., SCHWAB, R.S., VIETS, H.R., OSSERMAN, K.E. \& GENKINS, G. (1966). Myasthenia gravis: evaluation of treatment in 1,355 patients. Neurology(Minneapolis), 16, 431.

WARREN, C. \& PLANCHE, M.D. (1979). Myasthenia gravis in pregnancy: An update. American Journal of Obstetrics \& Gynecology, 135, 692. 